NBER WORKING PAPER SERIES

\title{
THE LONG-TERM COGNITIVE AND SCHOOLING EFFECTS OF CHILDHOOD VACCINATIONS IN CHINA
}

\author{
Hamid R. Oskorouchi \\ Alfonso Sousa-Poza \\ David E. Bloom \\ Working Paper 27217 \\ http://www.nber.org/papers/w27217 \\ NATIONAL BUREAU OF ECONOMIC RESEARCH \\ 1050 Massachusetts Avenue \\ Cambridge, MA 02138 \\ May 2020
}

Research reported in this working paper was supported by the National Institute on Aging of the National Institutes of Health (Award Number P30AG024409) and also by the Value of Vaccination Research Network (VoVRN), which is funded by a grant from the Bill \& Melinda Gates Foundation (Grant OPP1158136). The content is solely the responsibility of the authors and does not necessarily reflect the official views of the National Institutes of Health, the VoVRN, or the Bill \& Melinda Gates Foundation. We are also grateful to Arindam Nandi and Silvio Traverso for their comments and suggestions on an earlier version of this manuscript. The views expressed herein are those of the authors and do not necessarily reflect the views of the National Bureau of Economic Research.

NBER working papers are circulated for discussion and comment purposes. They have not been peer-reviewed or been subject to the review by the NBER Board of Directors that accompanies official NBER publications.

(c) 2020 by Hamid R. Oskorouchi, Alfonso Sousa-Poza, and David E. Bloom. All rights reserved. Short sections of text, not to exceed two paragraphs, may be quoted without explicit permission provided that full credit, including $(\odot$ notice, is given to the source. 
The Long-Term Cognitive and Schooling Effects of Childhood Vaccinations in China Hamid R. Oskorouchi, Alfonso Sousa-Poza, and David E. Bloom

NBER Working Paper No. 27217

May 2020

JEL No. I12,I18,I21

\begin{abstract}
By exploiting rich retrospective data on childhood immunization, socioeconomics, and health status in China (the China Health and Retirement Longitudinal Study), we assess the long-term effects of childhood vaccination on cognitive and educational outcomes in that country. To do so, we apply various techniques (e.g., propensity score and coarsened exact matching and correlated random effects) to different sets of conditioning variables and subsamples to estimate the average treatment on the treated effect of childhood vaccination. Our results confirm that vaccinations before the age of 15 have long-term positive and economically meaningful effects on nonhealth outcomes such as education and cognitive skills. These effects are relatively strong, with vaccinated individuals enjoying about one more year of schooling and performing substantially better later in life on several cognitive tests.
\end{abstract}

\author{
Hamid R. Oskorouchi \\ International Food Economics \\ and Rural Development \\ University of Göttingen \\ Germany \\ and University of Hohenheim \\ hamidreza.oskorouchi@uni-goettingen.de \\ Alfonso Sousa-Poza \\ Institute for Health Care \\ \& Public Management \\ University of Hohenheim \\ Germany \\ and Xi' an Jiaotong University \\ alfonso.sousa-poza@uni-hohenheim.de
}

\author{
David E. Bloom \\ Harvard T.H. Chan School of Public Health \\ Department of Global Health and Population \\ 665 Huntington Ave. \\ Building 1, Suite 1202 \\ Boston, MA 02115 \\ and NBER \\ dbloom@hsph.harvard.edu
}




\section{Introduction}

A review of 108 studies from 51 low- and middle-income countries amply demonstrates the economic benefits of vaccinations (Ozawa et al. 2012), estimating the cost of such immunization benefits as disease prevention and herd immunity to be less than USD1,000 per averted DALY. In addition, a growing number of epidemiological, immunological, and clinical studies indicate positive vaccine effects well beyond the intended disease protection (Benn et al. 2013, Saadatian-Elahi et al. 2016), including heterologous nonspecific protection via immune system training or induction of cross-reactive T-cells (Andersen et al. 2018). Because these nonspecific effects may be relatively substantial, they are just as-or even more-important for child mortality than specific vaccine effects (Benn et al. 2013). Hence, in assessing the effects of childhood vaccination on cognitive and schooling outcomes in late adulthood, we define as indirect any that affect nonhealth status outcomes (i.e., education and cognitive abilities) regardless of whether induced via targeted disease prevention (specific effects) or immune system boosting (nonspecific effects). The primary channel through which childhood vaccinations influence cognition and schooling is improved child health, which can raise educational outcomes through increased school attendance and achievement (Nandi, Shet, et al. 2019). The latter, in turn, can enhance cognitive skills not only in childhood, but also in later life, as the welldocumented association between schooling and old-age cognitive outcomes suggests (e.g., memory disorders; Glymour et al. 2008). A more direct effect of childhood health on cognitive skills relates to the detrimental effects of illnesses and stress on the hippocampus, which can negatively affect episodic memory performance in later life (Evans and Schamberg 2009, Hassevoort et al. 2016).

Our selected research setting of China provides a unique opportunity to assess childhood vaccination effects on late adulthood cognitive and educational outcomes because before Mao and the Chinese Communist Party assumed state power in 1949 (commonly termed the "Liberation"), immunization was extremely limited, infectious diseases extremely serious and difficult to control (Liang and Liu 2019a), and preventive medicine almost nonexistent in most of the country (Sidel and Sidel 1975). In 1950, however, the Ministry of Health oversaw a free smallpox vaccination campaign that achieved around $90 \%$ coverage nationwide within 3 years, followed in 1953 and 1954 by child vaccination directives against diphtheria toxoid and tuberculosis, respectively, together with accelerated research on vaccine development for all high-mortality infections. A key factor in the success of these campaigns was mass mobilization (World Bank 1984) driven by a Party policy that medicine should serve the needs of workers, peasants, and soldiers alike (Sidel and Sidel 1975), with preventive intervention prioritized over therapeutic. During the Cultural Revolution (1965-1975), however, immunization campaigns broke down because of a seriously depleted number of health technicians and lagging immunization oversight, resulting in poor or disrupted vaccination management (Liang and Liu 2019b). As a result, unlike vaccination practices in Europe and the United States, childhood immunization among older adults in China is nowhere near universal, providing the treatment variation necessary for the implementation of econometric techniques. The Chinese setting is doubly interesting in that its older populations often lack the high levels of cognitive ability inherently necessary for sound financial (and health) 
outcomes, while also having no access to specialist advice on such topics (Lei et al. 2014). At the same time, the threat to eldercare provision posed by past fertility reductions and migration patterns that increasingly separate parents geographically from their adult children make the promotion of cognitive health in China particularly important (Smith, Strauss, and Zhao 2014).

Our analysis, which draws on the China Health and Retirement Longitudinal Study (CHARLS), is to our knowledge the first comprehensive examination of the long-lasting effects of childhood vaccination on educational and cognitive outcomes in later adulthood. To measure these effects, we exploit a rich set of cognitive ability and schooling completion variables together with retrospective information on individual life histories, including vaccinations, and socioeconomic and health status during childhood. In estimating the average treatment on the treated effect (ATT) of childhood vaccination, we apply various techniques (propensity score and coarsened exact matching and correlated random effects) to different sets of conditioning variables and subsamples. Our results confirm that early life vaccination has long-term positive and economically meaningful effects on nonhealth outcomes such as educational achievement and cognitive skills. These effects are relatively strong, with vaccinated individuals enjoying about one more year of schooling and performing substantially better in later life on cognitive tests.

\section{Literature Review}

Whereas most literature on the effects of childhood vaccination focuses on child mortality rather than other outcomes, some recent studies do address the effects on cognitive and schooling outcomes. For example, in addition to inducing a 7.4 percentage point increase in male school enrollment probability in Bangladeshalbeit with no apparent effect for females (Driessen et al. 2015)-age-appropriate measles vaccination improves school grades in South Africa and enhances child anthropometry, cognition, and schooling outcomes in Ethiopia, India, and Vietnam relative to nonvaccinated children (Nandi, Shet, et al. 2019). Likewise, a study of the associations among these three outcomes and Hib vaccination in India documents significantly higher scores for vaccinated children on English, mathematics, reading, the Peabody Picture Vocabulary tests, and school grades, and higher z-scores for height-for-age (HAZ) and BMI-for-age (BMIZ; Nandi, Deolalikar, et al. 2019). This same pattern is observable among Filipino children given full childhood vaccination against measles; polio; tuberculosis (TB); and diphtheria, pertussis, and tetanus (DPT) (Bloom, Canning, and Shenoy (2011). Nandi et al. (2020) show that schooling attainment among young adults was improved (by about 0.25 grades) by exposure to India's Universal Immunization Programme (UIP), which took place between 1985 and 1990. Similarly, Anekwe et al. (2015) show that immunization increases years of schooling of young South Africans (6-11 years old) by 0.20 grades.

Not only do the aforementioned findings underscore vaccination's potential long-term benefits for cognition and schooling, but a large body of economics literature documents the financial benefits of good childhood health (e.g., Case, Fertig, and Paxson 2005, Smith 2009). For example, Case, Fertig, and Paxson (2005) show that even after they control for parental socioeconomic characteristics, those who experience poor health as 
children not only have poorer health as adults but also have significantly lower educational attainment and lower social status. Given the strength of these predominantly beneficial vaccine effects (both specific and nonspecific) on child health, such benefits could be expected to last the lifetime. Yet aside from the already cited studies, we know of no studies that assess the longer-lasting effects of vaccines, particularly those on nonhealth outcomes like cognitive ability and educational achievement. The only exception is the study of Nandi et al. (2020), which assesses how a specific vaccine affects adult education (adults aged between 20 and 49 years), but it neither investigates the effects on cognitive abilities, nor does focus on elderly individuals. Even the studies already referenced adopt a relatively short-term perspective by focusing primarily on outcomes in late childhood up to early adolescence rather than assessing the potential long-term effects in late adulthood.

Although this lack of empirical evidence on vaccination's long-term effects is no doubt related to the methodological challenges of identifying causal relations between childhood vaccines and later life outcomes, the randomized trials that should ideally be used to assess such effects are often very difficult to implement, especially many years after the original exposure (Barnighausen et al. 2014). Even the potential alternative of observational studies may suffer from selection bias if vaccine recipients differ from nonrecipients in ways that relate to the outcome variable independent of vaccination (Fine et al. 2009), prompting several researchers to mitigate this problem by using quasi-experimental propensity score matching (PSM; (e.g., Nandi, Shet, et al. 2019, Nandi, Deolalikar, et al. 2019, Bloom, Canning, and Shenoy 2011). Another way to avoid selection bias is to exploit natural experiments such as the introduction of universal vaccination programs, which guarantee that access to vaccines is independent of such bias-inducing factors as household wealth, parental education, and health insurance coverage (Andersen et al. 2018). An additional challenge when assessing vaccination's long-term implications is the widespread unavailability of precise childhood vaccination data for older adults. Our analysis thus makes a valuable contribution to the literature, not only by being one of the first to document the long-lasting effects of childhood vaccination on educational and cognitive outcomes, but also by applying a combination of techniques to limit possible biases. Our combination of several matching techniques with correlated random effects (CRE) regression, in particular, exploits the panel data structure to limit any possible skewing from time-invariant individual-level unobserved heterogeneity.

\section{Materials and Methods}

\subsection{Data}

Our data are drawn from CHARLS, a longitudinal survey representative of the Chinese population over age 45, which in addition to basic demographics collects information on the socioeconomic determinants of aging, including physical and physiological health. Our analysis uses both the three standard CHARLS waves (2011, 2013, and 2015) and a 2014 retrospective wave that provides family information; work history; and data on childhood education, health, and wealth status. In the main analysis of this study we retain only the observations for those aged less than or equal to 80 years old, but we report the results using the full sample in the Appendix. Excluding the so-called "super healthy" individuals from the sample is common in studies on 
elderly populations (c.f. Abeliansky and Strulik 2018), and it is done to limit selective mortality-related biases. In fact, especially for the case of China individuals older than 90 years old in our sample surpassed their life expectancy at birth.

Dependent variables. To estimate the long-term effects of childhood vaccination on cognitive abilities and education, we exploit episodic memory, mental status, and years of schooling as reflected by the cognitive ability measures in the three regular waves of the CHARLS panel data (see Table A.1 for the corresponding survey items). Specialized personnel collect these cognition measures, which match those used in internationally comparable surveys of older adults (e.g., Survey of Health and Retirement in Europe, also known as SHARE), with individual daily life reasoning abilities captured by episodic memory in the form of immediate and delayed recall. For these two variables, an enumerator reads a list of 10 Chinese nouns and then counts how many words on the list an individual can recall immediately and then four minutes later, respectively. For the purposes of our study, we transform these measures from count to quasi-normally distributed variables by computing the share of correctly recalled nouns out of the total listed (with the corresponding ATTs interpreted as the probability of correctly recalling all 10).

The second set of CHARLS cognitive ability measures, which comprises items from the Telephone Interview of Cognitive Status (TICS) study, proxies mental status by the ability to (i) name the day's date (year, month, day, and day of the week), (ii) redraw a picture, and (iii) count down from 100 by sevens up to five times (serial 7 subtraction, as a proxy for numeracy). Our econometric models employ this set of mental status variables (except for serial 7) in their original dichotomous form with a value of one indicating individual success on a specific task (zero otherwise). We then aggregate the episodic memory and mental status variables into two indicators representing the number of successfully accomplished tasks over the entire cognitive ability test (cf. McArdle, Smith, and Willis 2009). Lastly, because CHARLS specifies only a categorical variable for highest educational level achieved rather than exact years of formal education, we compute years of schooling by converting this level into actual years (cf. Molina 2016). According to Table 1, which reports the descriptive statistics for all the outcome variables measured, the treated respondents are always better off in terms of years of schooling, numeracy, episodic memory, and general mental status.

[Table 1 about here]

Main independent variable. The treatment in our models is childhood vaccination (i.e., before age 15), determined based on a corresponding item in the 2014 CHARLS retrospective wave, coded as one for vaccinated individuals (before age 15) and zero for unvaccinated, of which the latter comprise $36 \%$ of our sample (see Table 2). Unfortunately, because CHARLS provides no information on vaccination type and exact timing, we cannot construct variables that proxy vaccine-specific exposure, which would have allowed us to disentangle the biological mechanisms underlying our results. Nonetheless, knowing the timeline of vaccine introduction in China and exploiting the representativeness of our sample for older adults, we are able to narrow the pool of vaccines responsible for any positive effects on education and cognitive abilities. That is, given China's vaccine licensure timeline (Zheng et al. 2018) and our youngest respondent's 1970 birth year, 
the treatment group primarily received the antitubercular bacillus Calmette-Guérin (BCG, 1937); vaccines against plague (1946), yellow fever (1954), poliovirus (OPV, 1961), and measles (ML-L, 1965); and possibly the combined DTP immunization (1973).

[Table 2 about here]

Conditioning variables for PSM. For our PSM conditioning variables, we select a set of predictors of childhood vaccination probability whose vector includes demographic and childhood socioeconomic measures and parental characteristics (see Table A.2 for the corresponding CHARLS life history questions). These variables, together with their descriptive statistics and exogeneity with respect to the treatment variable, are detailed in the following Methods subsection.

Time-variant controls. To estimate the CRE models, we employ individual income and household food expenditure (per capita) as time-variant controls (in addition to age), derived from the CHARLS personal income and wealth and household expenditure modules, respectively, of which the latter include both purchased and self-produced food consumption. We correct both variables for inflation levels using the consumer price index (base year $=2010$ ).

\subsection{Methods}

The challenge in disentangling childhood vaccinations' long-term nonspecific effects on later life outcomes is that the parental attributes, of which childhood vaccination status is a function, might also determine better human and health capital in adulthood. Specifically, because the treatment (i.e., vaccination) is not randomly assigned, a naïve OLS model would produce upwardly biased estimates of the vaccination effect on the outcome variables studied. To avoid this bias, we employ a PSM technique that ensures the potential outcome's conditional independence by minimizing prevaccination background differences between the treatment and control groups to enable estimation of a causal ATT of childhood vaccination on human capital and later-life cognition. Although most Chinese in our sample were probably vaccinated in one of the nationwide immunization campaigns, two methodological considerations prevent us from exploiting these events as quasinatural experiments. First, because household socioeconomics and parental beliefs determine vaccination probability even when access is universally provided and incentivized, an empirical model unable to rely on random treatment assignment will produce biased estimates. Second, if the survey provides no precise information on immunization campaign enrollment, the timing of these events alone will not allow precise identification of the treated units (e.g., by exploiting birth year) because inoculation is not mandatory and applies to different age groups depending on the specific vaccine type and related campaign design.

Our PSM strategy thus first estimates vaccination probability on a set of regressors that proxy treatment probability while being exogenous to the treatment (e.g., household demographics and socioeconomic status in childhood). Then, retaining only those individuals who share a common support region, we estimate the ATT by alternatively applying k-nearest neighbor (k-NN), kernel, and Mahalanobis distance algorithms or by running OLS regressions that correct for potential bias via inverse probability of treatment weighting. In 
addition to PSM, we also estimate the childhood vaccination effect on educational and cognitive outcomes using an exact matching technique and exploit CHARLS's longitudinal structure by applying a correlated random effects model. Lastly, we test the robustness of our matching strategies through a series of placebo tests using outcome variables that are impervious to the treatment but strongly related to parental investment in children and adult attitudes toward health risk behaviors.

\subsection{Matching Strategy}

For a matching technique to produce unbiased ATT estimates, three assumptions must hold: First, to meet the balancing property (eq. 1), the groups of treated $(D=1)$ and control $(D=0)$ observations with the same propensity score $e(x)$ must be similar in their distribution of observable covariates $x$ (Rosenbaum and Rubin 1983):

$$
\operatorname{Pr}\{x \mid D=1, e(x)\}=\operatorname{Pr}\{x \mid D=0, e(x)\}
$$

Second, the matching must satisfy the conditional independence assumption (CIA) that given a set of explanatory variables $x$ that the treatment does not affect, the potential outcomes $Y(0)$ and $Y(1)$ are independent of treatment assignment $D=0,1$ (Caliendo and Kopeinig 2008):

$$
Y(0), Y(1) \Perp D|x=Y(0), Y(1) \Perp D| e(x)
$$

In the case of one continuous or multiple conditioning variable(s), the CIA (eq. 2, left side) is equally satisfied when the potential outcomes are independent of the treatment conditional on the propensity score (eq. 2, right side) (Rosenbaum and Rubin 1983). Lastly, for each treated observation a control observation with a similar $x$ or $e(x)$ must exist (Heckman, Ichimura, and Todd 1998), and if the analysis includes individuals outside the common support, the difference between the observed outcomes of the treatment and control groups are likely to be biased.

$$
0<\operatorname{Pr}(D=1 \mid x)<1
$$

Because the aforementioned constraints imply that the choice of propensity score conditioning variables is crucial to producing unbiased ATT estimates, we carefully select a set of explanatory variables that are impervious to the vaccination treatment while simultaneously determining the probability of immunization. This choice relies on a combination of the extant applied literature on vaccination determinants (e.g., Bloom, Canning, and Shenoy 2011) and the variables that best describe the Chinese context. We then estimate the propensity score by first running a set of probit regressions and then limiting any potential selection issue related to missing values by performing an independent PSM procedure for each outcome variable.

The explanatory variables selected are parental characteristics (both mother and father being illiterate and alive at the time of the most recent interview), demographic characteristics (gender, age, member of an ethnic minority group, and fixed effects for birth year), and health care access and socioeconomic status during childhood, as reflected by perceived socioeconomic status, experience of hunger, and no education before age 
15 (see Tables 2 and A.2 for variable descriptions). Although the original data characterize parental education by the highest formal schooling completed, more than $90 \%$ of the parents sampled have zero education or completed no primary schooling at all, prompting us to instead construct a dummy variable for literacy. We also construct a probit model that includes all possible interactions between the aforementioned regressors, except for birth year dummies. Because no probit conditioning variables (except age and mother and father being alive) vary in time, using the pooled panel sample for the propensity score computations has no advantage. In fact, given the slightly unbalanced nature of this panel dataset, all propensity score estimations use cross-sectional data that include each individual only once regardless of the number of waves in which the respondent was interviewed. The matching-based ATT estimations, in contrast, employ the full (pooled or longitudinal) sample.

Three aspects of our methodology give us confidence in the goodness of the conditioning variables, the first being our use of the predictive power of characteristics imbued at birth and not subsequently modifiable (e.g., age, gender, and ethnic minority membership) or impervious to the effects of childhood vaccination (mother/father literacy and mortality). The second is our use of variables that proxy socioeconomic status (poverty and hunger) under age 15, a period of probable economic inactivity, meaning that childhood vaccinations would not affect the family's economic status. The last is our proxying of both parental investment in child education and access to health care at the extensive margin (i.e., no education before age 15 and never seen by a doctor).

Although we can safely assume that childhood immunization status cannot be the cause of never having seen a doctor (especially in a sample of older adults), the exogeneity of the variable proxying childhood education must be carefully assessed. That is, some extant research suggests that certain vaccines (e.g., anti-influenza) improve school attendance (Pannaraj et al. 2014) and measles vaccine could increase the probability of school enrollment (Driessen et al. 2015), so even though we know of no studies demonstrating a vaccination effect on adult literacy, in rare cases of chronic disease (especially at the start of primary school), a lack of immunization could hypothetically translate into no formal education at all. Note also that $3 \%$ of those having no formal education before age 15 reported receiving 1-9 years of schooling in adulthood. The direction of the bias caused by including the potentially endogenous child education proxy among the set of conditioning variables would only lead to understated effects of childhood vaccination. Hence, to avoid any violation of the conditional exogeneity assumption, we replicate our analysis with the education variable excluded from the set of conditioning regressors, which yields estimates (Table A.3) that are virtually equivalent in statistical significance and magnitude to the main analytical findings reported in the Results section.

\subsection{Matching Algorithms}

Nearest neighbor matching (NN). To estimate the difference in observed outcomes, we use one-to-one NN propensity score to match each treated unit to the closest untreated control, permitting replacement to avoid biased estimates induced by the untreated pool representing only $15 \%$ of the total sample (i.e., having low 
matching quality). To ensure matching estimate precision, we then apply an oversampled k-NN that uses propensity score to pair each treated individual with the unweighted average of the eight closest controls.

Inverse probability weighting (IPW). The purpose of IPW is to balance the treatment and control groups by assigning larger weights to each treated (control) individual whose pretreatment characteristics are more likely to also occur in the set of controls (treated). That is, although the actual (inverse) treatment probability is unknown, it can be proxied by using a probit regression to compute a propensity score from which to construct a weighting system in which $w(x)=\frac{1}{e(x)}$ for treated individuals and $w(x)=\frac{1}{1-e(x)}$ for controls. ATT estimates can then be calculated using a regression model whose original estimator corrects for selection into treatment via the propensity score-based weights.

Kernel matching. Instead of building a counterfactual from equally weighted control individual(s), we adopt a kernel matching technique that enables the construction of a (nonparametrically) synthetic counterfactual by using a control set based on propensity score distance whose closest control is assigned greater weight. Our kernel matching estimations using an Epanechnikov (parabolic) weight system (see the Results section) yield very similar outcomes to (unreported) robustness checks based on a Gaussian kernel.

Local linear regression matching $(L L R)$. By locally fitting a line instead of a kernel constant, a nonparametric local linear regression solves two problems common to the latter approach: namely, bias dependency on the density of the propensity score distribution and bias boundary problems. Not only is LLR free of such dependency, but the potential bias is identical at both the interior points and boundaries of the distribution, thereby eliminating biases when the underlying model is truly linear (Fan 1992, 1993).

Mahalanobis metric matching. This matching technique uses a Mahalanobis geometric distance to pair treated units with control candidates. Unlike PSM procedures, which standardize the variables by exploiting the diagonal matrix of variances (Euclidian distance), the Mahalanobis metric matching uses the full variancecovariance matrix, meaning that it considers how the variables relate to each other (Rubin 1980). Such pairmatching methods are thus far more robust than mean-matching approaches (e.g., k-NN and kernel) in case of nonlinearities between the treatment and conditioning variables (Rubin 1979).

\subsection{Matching Quality Tests}

The descriptive statistics for the conditioning variables, reported in Table 2 for the full sample and treatment and control groups separately, are based on the largest subsample in the analysis: that used to estimate the effect of childhood vaccination on years of education. Applying multiple techniques to test the balance between these two groups (using Stata psmatch2 for all but stratification; (Leuven and Sianesi 2003)) reveals a considerable degree of imbalance. Hence, in Table 3 , we report the pseudo- $\mathrm{R}^{2}$, the overall standardized percentage mean bias and its statistical significance for each outcome variable and for the unmatched and matched samples. These results, based on our preferred matching specification using an oversampled k-NN algorithm $(K=8)$, first reveal that relatively few observations are dropped for being outside the common support 
region (20-109). They also show that just as the predictive power of our set of conditioning variables, as measured by the pseudo- $\mathrm{R}^{2}$, equals $7 \%$ before matching but drops to zero after matching, the standardized mean bias is always statistically significant and large in magnitude (24\%) before matching, but ranges between $1 \%$ and $2 \%$ after matching (albeit always statistically insignificant at $\alpha=5 \%$ ).

[Table 3 about here]

In support of these conclusions, Figure 1 graphs the matching quality for the subsample with no missing observations for years of schooling $(N=16,493)$, with Figure 1A depicting the standardized percentage bias broken down at the covariate level before and after matching (dots and crosses, respectively) and Figure 1B outlining these same results as the averages of the full set of conditioning variables. Figure 2 then plots the $\mathrm{CDF}$ of the propensity score before and after matching (Figure $2 \mathrm{~A}$ and $\mathrm{B}$, respectively) for our least conservative approach, the IPW. Comparing these distributions confirms our matching strategy's ability to balance pretreatment variables. Nevertheless, as an alternative test of this balancing ability, we conduct PSstratified $t$-tests (Dehejia and Wahba 2002), which calculate the propensity score by (probit) regressing the treatment variable on the full set of conditioning regressors, restricting the analysis to observations inside the common support region, and using a $t$-test to estimate the balance of each conditioning variable by propensity score block. The underlying assumption is that treatment and control group observations with similar propensity scores must also be similar in conditioning variable distribution (eq. 1). The number of blocks may be defined subjectively or by using the Stata pscore package to compute the optimal number of blocks and automatically running regression-based balancing $t$-tests $(\alpha=5 \%)$ for each conditioning variable across all PSblocks (Becker and Ichino 2002). Not only do all subsamples pass the balancing test, but when we consider only the main conditioning variables (i.e., excluding interactions and birth year dummies), all show perfect balance (zero percent unbalance), meaning no rejection of the null hypothesis of intergroup equality by block. Conversely, if we perform a balance test on the full set of 174 conditioning variables (including all possible interactions and birth year dummies) across all PS-blocks (12-15), the imbalance detected ranges only between $0.1 \%$ and $1 \%$, far below the $5 \%$ minimum threshold suggested in the literature.

[Figures $1 \& 2$ about here]

\subsection{Coarsened Exact Matching}

As an alternative to PSM, we estimate the effect of childhood vaccination on education and cognitive abilities using exact matching and coarsened exact matching techniques. For the former estimation strategy, we limit our set of conditioning variables to only those that are dichotomous (i.e., the original set of regressors except for age) and then exactly match each treated observation with a control unit. Alternatively, in line with some recent applied economics studies (e.g., Rellstab et al. 2020), we employ a coarsened exact matching technique to transform the age variable from continuous to categorical, using Stata cem to select an optimal number of categories (Blackwell et al. 2009). In these models, we exclude birth year fixed effects from the conditioning variable set to avoid a substantial loss of observations. We derive the final ATT using IPW cem-based 
regressions that exploit the weighting obtained from either the exact or the coarsened exact matching strategies. Because by construction no difference exists in pretreatment characteristics between treatment and control groups, both these methods automatically fulfil the balancing property. Admittedly, a frequent drawback of (coarsened) exact matching is smaller sample size; however, in our case, once the treated individuals are matched exactly with their control counterparts, we are able to retain an acceptable number of observations.

\subsection{Correlated Random Effects}

To limit any possible bias from time-invariant individual-level unobserved heterogeneity, we exploit the longitudinal nature of our dataset by estimating CRE regressions in an IPW framework. We do so not only because our treatment variable, being fixed in time, precludes the use of a fixed effects model, but because in a random effects framework, the CRE approach controls for the average of the time-variant independent variables, meaning that in a balanced panel setting, the CRE estimator of the time-variant variables is equivalent to the within-estimator (Mundlak 1978). We apply this method by first using the cross-sectional sample to estimate a propensity score, computing the inverse treatment probability, and then running a CRE model (in Stata xtregre2; (Merryman 2005)) that accounts for these weights plus a set of time-variant and fixed control variables. The only caveat is that the time-invariant nature of our schooling proxy prevents estimation of the childhood vaccination effect on education. However, CRE models use a smaller sample than pooled PSM, not only because the CRE list-wise approach to data preparation for the time-variant controls causes the loss of some observations $(1,004)$, but because it drops all individuals not interviewed at least twice.

\section{Results}

According to Tables 4 and 5, which report the PSM and exact matching estimations for the childhood vaccination effect on schooling and cognitive abilities among older Chinese, neither the magnitude nor the statistical significance vary substantially regardless of matching strategy employed. Nonetheless, k-NN matching $(k=8)$ proves the preferred method because it assures the highest degree of balance between the conditioning variables. All ATT estimates, independent of matching strategy, are positive and statistically significant at the $5 \%$ level. The estimates reported as follows must be interpreted as probabilities for all the dichotomous variables, as points of scores ranging from zero to one for the numeracy, episodic memory, and mental status, and as years of schooling for the education variable.

Not only do we estimate the extensive margin of the childhood vaccination effect on schooling to be approximately one extra year, but we show that the treatment considerably increases the numeracy score by 0.06 points, as measured by the serial 7 test, and the ability to redraw a geometric figure ( $9 \%$ higher probability). As regards the variables that proxy mental status, correctly naming the current year and day of the week show the largest effects at $6.4 \%$ and $7.4 \%$ higher probabilities, respectively, whereas those for month and day of the month are only around 3\%. These results are in line with the expectation that childhood vaccinations contribute not only to better mental status in late adulthood, but also to a more active life: active individuals, regardless of mental status, are more likely to know the day of the week. The aggregate indicators 
for mental health and episodic memory further confirm these results, pointing respectively to a 0.04 points treatment-induced increase in the mental status score and a 0.06 points improvement in episodic memory. This latter holds irrespective of whether assessed by immediate or delayed recall, reflecting 0.03 and 0.04 points higher episodic memory scores, respectively. Nonetheless, when comparing the PSM ATTs (Table 4) to those obtained via (coarsened) exact matching (Table 5), the need to drop 6-17\% of the original sample dependent on matching strategy raises the possibility of sample selection (see the bottom of Table 5 for dropped observations by treatment group). Despite this drawback, these estimates remain virtually equivalent to the PSM ATTs in terms of both statistical significance and magnitude, while also being consistent with those from our CRE model for longitudinal data weighted by inverse treatment probability reported in Table 6 . This latter is particularly relevant given the CRE estimator's ability to account for time-invariant unobserved heterogeneity, a problem that the matching strategies cannot solve. Moreover, because we directly control for meaningful time-variant predictors of cognitive ability at the time of interview (i.e., personal income and household food consumption), we can claim that the degree of bias originating from time-variant heterogeneity is probably minimal.

[Tables $4,5 \& 6$ about here]

To confirm the robustness of our estimates, we perform a series of placebo tests using variables based on individual smoking history and number of living biological siblings (excluding individuals who never had siblings). According to the outcome summary statistics (see Table 7), which include the mean difference between treatment and control groups and its statistical significance, control group members are 5\% more likely to be or have been smokers and $6 \%$ less likely to have living biological siblings. We thus consider these two variables ideal measures for placebo testing. Because childhood vaccination should not affect the individual probability of ever having been a smoker and is unlikely to have strongly affected sibling health status (e.g., premature death), any statistically significant effect detected by the placebo tests would suggest that our strategy inadequately corrects for parental background characteristics and/or adult health risk behavior. In fact, as Table 8 shows, the results-obtained using all eight of our methodological approaches-not only yield ATTs of very small magnitude (especially compared with the biased intergroup mean differences in Table 7), but also coefficients that remain statistically insignificant even at $\alpha=10 \%$.

[Tables $7 \& 8$ about here]

Although our estimation strategy is admittedly limited by its inability to address the bias from excluding those who suffered premature death due to lack of immunization, because the treatment considered is beneficial, this exclusion should at worst lead to underestimation of vaccination's true positive effect on education and cognitive abilities. In fact, in our setting, because the nonimmunized dead, had they lived, would presumably have been less healthy and more disadvantaged in terms of schooling year completion, they would have belonged to-and lowered the variable mean for-the control group, causing our ATTs to underestimate the true vaccination effect. Finally, the PSM results remain virtually unchanged when using the full sample of 
individuals (i.e., including those up to 90 years of age) or excluding the childhood education proxy from the set of conditioning variables. Tables A.3 and A.4 report these additional results respectively. As expected, although the ATT estimates in Table A.3 do not change either in terms of sign or statistical significance, their magnitude is on average larger than the main results reported in Table 4. We cannot state with certainty if the exclusion of the (possibly endogenous) childhood education proxy from the set of conditioning PSM variables corrects a downward bias in the main results (Table 4), or if its inclusion allows us to construct a better PSbased control group. In any case, in the main text we present the most conservative estimates. Finally, the results using the sample of individuals up to 90 years of age reported in Table A.4 confirm the robustness of our main results. Unsurprisingly, the inclusion of older individuals slightly reduces the effect of childhood vaccination on schooling. However, these results are more likely to suffer from selective mortality-related biases because of the inclusion of the super healthy. Finally, the statistical significance of our results holds for every estimation strategy and dependent variable considered even when we correct the p-values for multiple testing. Results of a Benjamini and Hochberg (1995) procedure alternatively using 0.05 and 0.25 false discovery rates are available on request.

\section{Discussion and Conclusions}

By analyzing data from the China Health and Retirement Longitudinal Study, we find that adults over age 45 who were vaccinated before the age of 15 tend to perform better on standardized cognitive tests and complete more years of schooling than similar unvaccinated individuals. These effects are relatively strong, with vaccinated individuals having enjoyed about one more year of schooling and performing substantially better on several cognitive tests, including 0.06 points higher numeracy and episodic memory scores. These findings, which remain robust and statistically significant regardless of matching algorithm even after we account for vaccination's possible confounding effects, reinforce the existing evidence on vaccination's health, cognition, and schooling effects in myriad countries, such as the additional $0.2-0.3$ school grade by age 12 among Indian children age-appropriately vaccinated for measles (Nandi, Shet, et al. 2019). In particular, our analysis highlights that such benefits, which in China translate into approximately one more year of schooling, are long lasting and persistent into older age. These results are in line with a recent study demonstrating that childhood infections (more likely to occur among non-immunized individuals) decrease earnings and years of employment in adulthood (Viinikainen et al. 2020).

In addition, by comparing the effect size of our results with those in other studies that use the CHARLS survey and assessing how other conditions or shocks measured at their extensive margin affect the episodic memory and mental status of older Chinese adults, we demonstrate that early vaccination's positive effects on cognitive outcomes are substantial.

In a study of widowhood's effect on cognitive functions in older Chinese, Zhang and colleagues conclude that continual widowhood status (i.e., across every data wave) decreases the episodic memory score by 0.15 points, while having any functional physical limitation lowers it by 0.17 points (Zhang, Li, et al. 2019). In this present study, by constructing a similar index for comparative purposes (i.e., the actual number of recalled words 
instead of their share), we show that early vaccination increases the score by $0.30-0.43$ points, thereby offsetting the joint negative effect of widowhood status and functional limitation by $93-134 \%$. In another cross-sectional study for China, Zhang, Yang, et al. (2019), after adjusting for sociodemographics and cardiovascular diseases, identify a negative association between untreated diabetes and episodic memory, with a decrease of 0.19 and 0.47 for the full and 45-69 year old samples, respectively. The magnitude of our results can also be considered significant when compared with findings on factors that positively affect cognitive abilities; for example, a 0.18 higher serial 7 numeracy score induced by playing Mahjong or chess (Kesavayuth, Liang, and Zikos 2018), compared with our finding of a 0.065-0.085 (38-47\%) improvement from childhood vaccination. By comparing the size of the vaccination effect on memory status in our study with the results reported by Pan and Chee (2019), we can infer that among older Chinese, childhood vaccination is twice as beneficial as engaging in one extra social activity (e.g., voluntary work, interaction with friends, educational courses, or sports). Lastly, our results on education relate to the findings of Nandi et al. (2020) on the effect of childhood exposure to the Indian UIP on schooling of young adults. In their paper, these effects range from 0.18 to 0.29 more schooling grades, depending on the econometric specification. In our study, the same results are comparatively larger (approximately one extra year of schooling). This difference in magnitude can be justified only marginally by the treatment heterogeneity between the studies. In fact, the treatment group in Nandi et al. (2020) was exposed to a similar set of vaccines as the treatment group in this study (i.e., ML-L, BCG, OPV, DPT), but likely with different timings and doses. Rather, the greater magnitude found in our analysis of Chinese elderly might be explained by convergence in schooling. That is, as with income growth, countries with lower average education would experience faster schooling growth than in relatively highly educated countries. This implies that the potential (in years of schooling) of a given investment in education is greater in less educated populations. Currently China and India do not diverge much in terms of gross secondary schooling enrollment. However, the average years of schooling in the Indian study treatment sample equals 10.29 years, whereas the same figure for the sample of treated Chinese in our study is only 5.41, a divergence that can be explained by the different cohorts analyzed in the two studies.

Despite such significant effects, however, we consider our effects conservative, not only because we do not account for herd immunity-the indirect protection from infectious disease provided by treated individuals to untreated controls-but also because we cannot control for the selective mortality that would dilute childhood vaccination's beneficial effects. The CRE model, unlike the PSM, allows us to address time-invariant unobserved heterogeneity, but the possibility of time-variant unobserved heterogeneity remains a limitation of our analysis. Despite these limitations, however, we believe that our application of several matching techniques to such a rich set of child and household covariates represents the most viable-perhaps even the only-way of accurately assessing the effects of childhood experiences on later life outcomes.

Given the approximately $8 \%$ increase in earnings induced by each extra year of schooling in China (Giles, Park, and Wang 2019), the vaccination effect on cognitive abilities and educational outcomes could imply economic benefits, particularly if, as our results suggest, childhood vaccines improve cognitive aging, thereby 
preventing or postponing cognitive decline into dementia (Petersen et al. 2009). Childhood vaccination may also help to reduce dementia's economic burden while reducing wealth and health inequities by lowering morbidity and mortality (Andre et al. 2008). In fact, according to our results, the beneficial effects of vaccines on cognition and educational outcomes may even amplify inequality reduction, especially in the face of 19 million children worldwide who in 2018 received no routine immunizations (WHO 2019). We thus hope that, at a time when growing public vaccination hesitancy is lowering herd immunity in both high- and middle-lowincome countries (Vaccine hesitancy 2019), the robust evidence provided here of vaccination's long-term beneficial effects will mitigate reluctance and increase the demand for immunization.

\section{References}

Abeliansky, A. L., and H. Strulik. 2018. "Hungry children age faster." Econ Hum Biol 29:211-220. doi: 10.1016/j.ehb.2018.03.005.

Andersen, Andreas, Ane Baerent Fisker, Amabelia Rodrigues, Cesario Martins, Henrik Ravn, Najaaraq Lund, Sofie Biering-Sørensen, Christine Stabell Benn, and Peter Aaby. 2018. "National immunization campaigns with oral polio vaccine reduce all-cause mortality: a natural experiment within seven randomized trials." Frontiers in public health 6:13.

Andre, F. E., R. Booy, H. L. Bock, J. Clemens, S. K. Datta, T. J. John, B. W. Lee, S. Lolekha, H. Peltola, T. A. Ruff, Mathuram Santosham, and H. J. Schmitt. 2008. "Vaccination greatly reduces disease, disability, death and inequity worldwide." Bulletin of the World Health Organization 86 (2):140-146. doi: 10.2471/BLT.07.040089.

Anekwe, Tobenna D., Marie-Louise Newell, Frank Tanser, Deenan Pillay, and Till Bärnighausen. 2015. "The causal effect of childhood measles vaccination on educational attainment: A mother fixed-effects study in rural South Africa." Vaccine 33 (38):5020-5026. doi: 10.1016/j.vaccine.2015.04.072.

Barnighausen, T., D. E. Bloom, E. T. Cafiero-Fonseca, and J. C. O'Brien. 2014. "Valuing vaccination." Proc Natl Acad Sci U S A 111 (34):12313-9. doi: 10.1073/pnas.1400475111.

Benjamini, Yoav, and Yosef Hochberg. 1995. "Controlling the false discovery rate: a practical and powerful approach to multiple testing." Journal of the Royal statistical society: series B (Methodological) 57 (1):289-300.

Becker, S. O., and A. Ichino. 2002. "Estimation of average treatment effects based on propensity scores." Stata Journal 2 (4):358-377. doi: Doi 10.1177/1536867x0200200403.

Benn, C. S., M. G. Netea, L. K. Selin, and P. Aaby. 2013. "A small jab - a big effect: nonspecific immunomodulation by vaccines." Trends Immunol 34 (9):431-9. doi: 10.1016/j.it.2013.04.004.

Blackwell, M., S. lacus, G. King, and G. Porro. 2009. "cem: Coarsened exact matching in Stata." Stata Journal 9 (4):524-546. doi: Doi 10.1177/1536867x0900900402.

Bloom, David E., David Canning, and Erica S. Shenoy. 2011. "The effect of vaccination on children's physical and cognitive development in the Philippines." Applied Economics 44 (21):2777-2783. doi: 10.1080/00036846.2011.566203.

Caliendo, Marco, and Sabine Kopeinig. 2008. "Some practical guidance for the implementation of propensity score matching." Journal of economic surveys 22 (1):31-72.

Case, A., A. Fertig, and C. Paxson. 2005. "The lasting impact of childhood health and circumstance." J Health Econ 24 (2):365-89. doi: 10.1016/j.jhealeco.2004.09.008.

Dehejia, R. H., and S. Wahba. 2002. "Propensity score-matching methods for nonexperimental causal studies." Review of Economics and Statistics 84 (1):151-161. doi: Doi 10.1162/003465302317331982.

Driessen, J., A. Razzaque, D. Walker, and D. Canning. 2015. "The effect of childhood measles vaccination on school enrolment in Matlab, Bangladesh." Applied Economics 47 (55):6019-6040. doi: 10.1080/00036846.2015.1061647. 
Evans, G. W., and M. A. Schamberg. 2009. "Childhood poverty, chronic stress, and adult working memory." Proc Natl Acad Sci U S A 106 (16):6545-9. doi: 10.1073/pnas.0811910106.

Fan, J. Q. 1992. "Design-Adaptive Nonparametric Regression." Journal of the American Statistical Association 87 (420):998-1004. doi: Doi 10.2307/2290637.

Fan, J. Q. 1993. "Local Linear-Regression Smoothers and Their Minimax Efficiencies." Annals of Statistics 21 (1):196-216. doi: DOI 10.1214/aos/1176349022.

Fine, P. E., T. N. Williams, P. Aaby, K. Kallander, L. H. Moulton, K. L. Flanagan, P. G. Smith, C. S. Benn, and Working Group on Non-specific Effects of Vaccines. 2009. "Epidemiological studies of the 'nonspecific effects' of vaccines: data collection in observational studies." Trop Med Int Health 14 (9):96976. doi: 10.1111/j.1365-3156.2009.02301.x.

Giles, John, Albert Park, and Meiyan Wang. 2019. "The Great Proletarian Cultural Revolution, Disruptions to Education, and the Returns to Schooling in Urban China." Economic Development and Cultural Change 68 (1):131-164. doi: 10.1086/700568.

Glymour, M. M., I. Kawachi, C. S. Jencks, and L. F. Berkman. 2008. "Does childhood schooling affect old age memory or mental status? Using state schooling laws as natural experiments." J Epidemiol Community Health 62 (6):532-7. doi: 10.1136/jech.2006.059469.

Hassevoort, K. M., N. A. Khan, C. H. Hillman, and N. J. Cohen. 2016. "Childhood Markers of Health Behavior Relate to Hippocampal Health, Memory, and Academic Performance." Mind Brain and Education 10 (3):162-170. doi: 10.1111/mbe.12108.

Heckman, J. J., H. Ichimura, and P. Todd. 1998. "Matching as an econometric evaluation estimator." Review of Economic Studies 65 (2):261-294. doi: Doi 10.1111/1467-937x.00044.

Kesavayuth, D., Y. Liang, and V. Zikos. 2018. "An active lifestyle and cognitive function: Evidence from China." Journal of the Economics of Ageing 12:183-191. doi: 10.1016/j.jeoa.2018.05.001.

Lei, X., J. P. Smith, X. Sun, and Y. Zhao. 2014. "Gender Differences in Cognition in China and Reasons for Change over Time: Evidence from CHARLS." J Econ Ageing 4:46-55. doi: 10.1016/j.jeoa.2013.11.001.

PSMATCH2: Stata module to perform full Mahalanobis and propensity score matching, common support graphing, and covariate imbalance testing S432001, revised 01 Feb 2018. College Department of Economics, Boston.

Liang, Xiaofeng, and Yanmin Liu. 2019a. "My Experience as Director of the National Immunization Program (Historical Review)." In Immunization Program in China, edited by Xiaofeng Liang, 1-14. Singapore: Springer Singapore.

Liang, Xiaofeng, and Yanmin Liu. 2019b. "My Experience as Director of the National Immunization Program (Historical Review)." In Immunization Program in China, 1-14. Springer.

McArdle, John J, James P Smith, and Robert Willis. 2009. Cognition and economic outcomes in the Health and Retirement Survey. In NBER Working Papers: National Bureau of Economic Research.

XTREGRE2: Stata module to estimate random effects model with weights S456514. Boston College Department of Economics.

Molina, T. 2016. "Reporting Heterogeneity and Health Disparities Across Gender and Education Levels: Evidence From Four Countries." Demography 53 (2):295-323. doi: 10.1007/s13524-016-0456-z.

Mundlak, Yair. 1978. "On the pooling of time series and cross section data." Econometrica: journal of the Econometric Society 46 (1):69-85.

Nandi, A., A. B. Deolalikar, D. E. Bloom, and R. Laxminarayan. 2019. "Haemophilus influenzae type b vaccination and anthropometric, cognitive, and schooling outcomes among Indian children." Ann N Y Acad Sci 1449 (1):70-82. doi: 10.1111/nyas.14127.

Nandi, A., A. Shet, J. R. Behrman, M. M. Black, D. E. Bloom, and R. Laxminarayan. 2019. "Anthropometric, cognitive, and schooling benefits of measles vaccination: Longitudinal cohort analysis in Ethiopia, India, and Vietnam." Vaccine 37 (31):4336-4343. doi: 10.1016/j.vaccine.2019.06.025.

Nandi, Arindam, Santosh Kumar, Anita Shet, David E Bloom, and Ramanan Laxminarayan. 2020. "Childhood vaccinations and adult schooling attainment: Long-term evidence from India's Universal Immunisation Programme." Social Science \& Medicine:112885. 
Ozawa, S., A. Mirelman, M. L. Stack, D. G. Walker, and O. S. Levine. 2012. "Cost-effectiveness and economic benefits of vaccines in low- and middle-income countries: a systematic review." Vaccine 31 (1):96108. doi: 10.1016/j.vaccine.2012.10.103.

Pan, X., and K. H. Chee. 2019. "The power of weak ties in preserving cognitive function: a longitudinal study of older Chinese adults." Aging Ment Health:1-8. doi: 10.1080/13607863.2019.1597015.

Pannaraj, P. S., H. L. Wang, H. Rivas, H. Wiryawan, M. Smit, N. Green, G. M. Aldrovandi, A. N. El Amin, and L. Mascola. 2014. "School-located influenza vaccination decreases laboratory-confirmed influenza and improves school attendance." Clin Infect Dis 59 (3):325-32. doi: 10.1093/cid/ciu340.

Petersen, R. C., R. O. Roberts, D. S. Knopman, B. F. Boeve, Y. E. Geda, R. J. Ivnik, G. E. Smith, and C. R. Jack, Jr. 2009. "Mild cognitive impairment: ten years later." Arch Neurol 66 (12):1447-55. doi: 10.1001/archneurol.2009.266.

Rellstab, S., P. Bakx, P. Garcia-Gomez, and E. van Doorslaer. 2020. "The kids are alright - labour market effects of unexpected parental hospitalisations in the Netherlands." J Health Econ 69:102275. doi: 10.1016/j.jhealeco.2019.102275.

Rosenbaum, P. R., and D. B. Rubin. 1983. "The Central Role of the Propensity Score in Observational Studies for Causal Effects." Biometrika 70 (1):41-55. doi: DOI 10.1093/biomet/70.1.41.

Rubin, D. B. 1979. "Using Multivariate Matched Sampling and Regression Adjustment to Control Bias in Observational Studies." Journal of the American Statistical Association 74 (366):318-328. doi: Doi 10.2307/2286330.

Rubin, D. B. 1980. "Bias Reduction Using Mahalanobis-Metric Matching." Biometrics 36 (2):293-298. doi: Doi $10.2307 / 2529981$.

Saadatian-Elahi, M., P. Aaby, F. Shann, M. G. Netea, O. Levy, J. Louis, V. Picot, M. Greenberg, and W. Warren. 2016. "Heterologous vaccine effects." Vaccine 34 (34):3923-30. doi: 10.1016/j.vaccine.2016.06.020.

Sidel, Victor W, and Ruth Sidel. 1975. "The health care delivery system of the People's Republic of China." World Development, 3 (7-8):539-549.

Smith, J. P. 2009. "The Impact of Childhood Health on Adult Labor Market Outcomes." Rev Econ Stat 91 (3):478-489. doi: 10.1162/rest.91.3.478.

Smith, J. P., J. Strauss, and Y. Zhao. 2014. "Healthy Aging in China." J Econ Ageing 4:37-43. doi: 10.1016/j.jeoa.2014.08.006.

Vaccine hesitancy. 2019. "Vaccine hesitancy." The Lancet Child \& Adolescent Health 3 (5):281.

Viinikainen, Jutta, Alex Bryson, Petri Böckerman, Marko Elovainio, Nina Hutri-Kähönen, Markus Juonala, Terho Lehtimäki, Katja Pahkala, Suvi Rovio, and Laura Pulkki-Råback. 2020. "Do childhood infections affect labour market outcomes in adulthood and, if so, how?" Economics \& Human Biology 37:100857.

WHO. 2019. "Immunization coverage." accessed 31.03.2020. https://www.who.int/news-room/factsheets/detail/immunization-coverage.

World Bank. 1984. The Health Sector in China. Washington, DC: Population, Health and Nutrition Department, World Bank.

Zhang, L., J. Yang, Z. Liao, X. Zhao, X. Hu, W. Zhu, and Z. Zhang. 2019. "Association between Diabetes and Cognitive Function among People over 45 Years Old in China: A Cross-Sectional Study." Int J Environ Res Public Health 16 (7):1294. doi: 10.3390/ijerph16071294.

Zhang, Zhenmei, Lydia W Li, Hongwei Xu, and Jinyu Liu. 2019. "Does widowhood affect cognitive function among Chinese older adults?" SSM-population health 7:100329.

Zheng, Y., L. Rodewald, J. Yang, Y. Qin, M. Pang, L. Feng, and H. Yu. 2018. "The landscape of vaccines in China: history, classification, supply, and price." BMC Infect Dis 18 (1):502. doi: 10.1186/s12879-018-34220. 
Table 1 Descriptive statistics: outcome variables by treatment group

\begin{tabular}{l|cc|cc|cc|cc}
\hline \multirow{2}{*}{\multicolumn{1}{c|}{ Variable }} & \multicolumn{2}{|c|}{ Full sample } & \multicolumn{2}{c|}{ Treated } & \multicolumn{2}{c|}{ Control } & \multicolumn{2}{c}{ Before matching } \\
\cline { 2 - 8 } & Mean & SD & Mean & SD & Mean & SD & Difference & T-test \\
\hline Years of schooling & 5.07 & 4.11 & 5.41 & 4.10 & 3.12 & 3.62 & 2.29 & 27.11 \\
Drawing & 0.67 & 0.47 & 0.70 & 0.46 & 0.50 & 0.50 & 0.20 & 19.36 \\
Serial 7 & 0.28 & 0.20 & 0.30 & 0.20 & 0.22 & 0.20 & 0.07 & 17.87 \\
Name year & 0.76 & 0.43 & 0.79 & 0.41 & 0.63 & 0.48 & 0.16 & 17.16 \\
Name month & 0.86 & 0.34 & 0.87 & 0.33 & 0.81 & 0.40 & 0.07 & 8.76 \\
Name day & 0.61 & 0.49 & 0.64 & 0.48 & 0.49 & 0.50 & 0.14 & 13.25 \\
Name weekday & 0.74 & 0.44 & 0.75 & 0.43 & 0.67 & 0.47 & 0.08 & 8.43 \\
Immediate recall & 0.41 & 0.18 & 0.41 & 0.17 & 0.35 & 0.17 & 0.06 & 16.25 \\
Delayed recall & 0.31 & 0.20 & 0.32 & 0.20 & 0.25 & 0.19 & 0.07 & 15.46 \\
Mental health & 0.07 & 0.29 & 0.08 & 0.28 & 0.61 & 0.31 & 0.12 & 29.85 \\
Episodic memory & 0.34 & 0.18 & 0.36 & 0.17 & 0.35 & 0.18 & 0.69 & 27.85 \\
\hline
\end{tabular}

Notes: Estimates obtained using the CHARLS cross-sectional sample of observations present in the respective outcome considered. SD, standard deviation.

Table 2 Descriptive statistics of conditioning, treatment, and time-changing variables

\begin{tabular}{l|cc|cc|cc|cc}
\hline \multirow{2}{*}{\multicolumn{1}{c|}{ Variable }} & \multicolumn{2}{|c|}{ Full sample } & \multicolumn{2}{c|}{ Treated } & \multicolumn{2}{c|}{ Control } & \multicolumn{2}{c}{ Before matching } \\
\cline { 2 - 9 } & Mean & SD & Mean & SD & Mean & SD & Difference & T-test \\
\hline Mother illiterate & 0.83 & 0.37 & 0.82 & 0.38 & 0.90 & 0.30 & -0.08 & -10.21 \\
Father illiterate & 0.58 & 0.49 & 0.56 & 0.50 & 0.71 & 0.45 & -0.15 & -14.72 \\
Mother alive & 0.27 & 0.44 & 0.29 & 0.45 & 0.18 & 0.38 & 0.11 & 12.00 \\
Father alive & 0.15 & 0.36 & 0.17 & 0.37 & 0.09 & 0.29 & 0.08 & 10.05 \\
Poor in childhood & 0.39 & 0.49 & 0.39 & 0.49 & 0.44 & 0.50 & -0.05 & -4.92 \\
Male & 0.49 & 0.50 & 0.50 & 0.50 & 0.42 & 0.49 & 0.08 & 7.86 \\
Hunger in childhood & 0.82 & 0.38 & 0.83 & 0.38 & 0.78 & 0.41 & 0.04 & 5.13 \\
Age & 56.94 & 9.11 & 56.23 & 8.78 & 61.01 & 9.91 & -4.78 & -25.48 \\
Ethnic minority & 0.08 & 0.27 & 0.08 & 0.27 & 0.09 & 0.29 & -0.01 & -2.60 \\
Never in hospital & 0.04 & 0.19 & 0.03 & 0.18 & 0.05 & 0.22 & -0.02 & -4.66 \\
No child education & 0.19 & 0.40 & 0.17 & 0.37 & 0.36 & 0.48 & -0.19 & -23.47 \\
Vaccine & 0.84 & 0.36 & - & - & - & - & - & - \\
Income (10,000 ¥) & 0.56 & 1.94 & 0.54 & 1.98 & 0.20 & 0.77 & 0.34 & 13.68 \\
Food (10,000 $¥)$ & 0.04 & 0.12 & 0.04 & 0.07 & 0.03 & 0.08 & 0.004 & 4.12 \\
\hline
\end{tabular}

Notes: Estimates obtained using the CHARLS cross-sectional sample of observations present in the years of schooling variable $(N=16,602)$. SD, standard deviation. 


\section{Dependent variable $\quad$ Sample $\quad$ Pseudo $R^{2} \quad$ Mean bias (\%) $\quad$ p>chi2 $\quad$ On support $\quad$ Off support}

\begin{tabular}{|c|c|c|c|c|c|c|}
\hline \multirow{2}{*}{ Schooling (in years) } & Unmatched & 0.07 & 23.9 & 0.000 & & \\
\hline & Matched & 0.00 & 1.2 & 0.213 & 16,493 & 109 \\
\hline \multirow{2}{*}{ Draw } & Unmatched & 0.07 & 23.3 & 0.000 & & \\
\hline & Matched & 0.00 & 1.3 & 0.052 & 15,186 & 60 \\
\hline \multirow{2}{*}{ Serial 7} & Unmatched & 0.07 & 23.4 & 0.000 & & \\
\hline & Matched & 0.00 & 0.9 & 0.779 & 15,376 & 63 \\
\hline \multirow{2}{*}{ Name year } & Unmatched & 0.07 & 23.3 & 0.000 & & \\
\hline & Matched & 0.00 & 1 & 0.540 & 15,114 & 84 \\
\hline \multirow{2}{*}{ Name month } & Unmatched & 0.06 & 21.5 & 0.000 & & \\
\hline & Matched & 0.00 & 1.3 & 0.147 & 15,229 & 55 \\
\hline \multirow{2}{*}{ Name weekday } & Unmatched & 0.07 & 23.2 & 0.000 & & \\
\hline & Matched & 0.00 & 1.4 & 0.183 & 15,062 & 85 \\
\hline \multirow{2}{*}{ Name day } & Unmatched & 0.07 & 23.3 & 0.000 & & \\
\hline & Matched & 0.00 & 1 & 0.687 & 15,110 & 87 \\
\hline \multirow{2}{*}{ Immediate word recall } & Unmatched & 0.07 & 23.3 & 0.000 & & \\
\hline & Matched & 0.00 & 1.6 & 0.069 & 14,280 & 102 \\
\hline \multirow{2}{*}{ Delayed word recall } & Unmatched & 0.07 & 23.4 & 0.000 & & \\
\hline & Matched & 0.00 & 1.3 & 0.356 & 14,283 & 87 \\
\hline \multirow{3}{*}{ Episodic memory } & Unmatched & 0.06 & 21.8 & 0.000 & & \\
\hline & Matched & 0.00 & 1.2 & 0.190 & 14,359 & 51 \\
\hline & Unmatched & 0.06 & 21.8 & 0.000 & & \\
\hline Mental health & Matched & 0.00 & 0.9 & 0.439 & 15,146 & 102 \\
\hline \multirow{2}{*}{ Ever smoked } & Unmatched & 0.07 & 22.4 & 0.000 & & \\
\hline & Matched & 0.00 & 1.0 & 0.139 & 16,648 & 59 \\
\hline \multirow{2}{*}{ Share of living sibling } & Unmatched & 0.07 & 22.2 & 0.000 & & \\
\hline & Matched & 0.00 & 1.2 & 0.667 & 15,940 & 63 \\
\hline
\end{tabular}

Notes: Estimates obtained using the CHARLS cross-sectional sample of observations present in the respective outcome considered. 
Figure 1 Balance of conditioning variables before and after matching

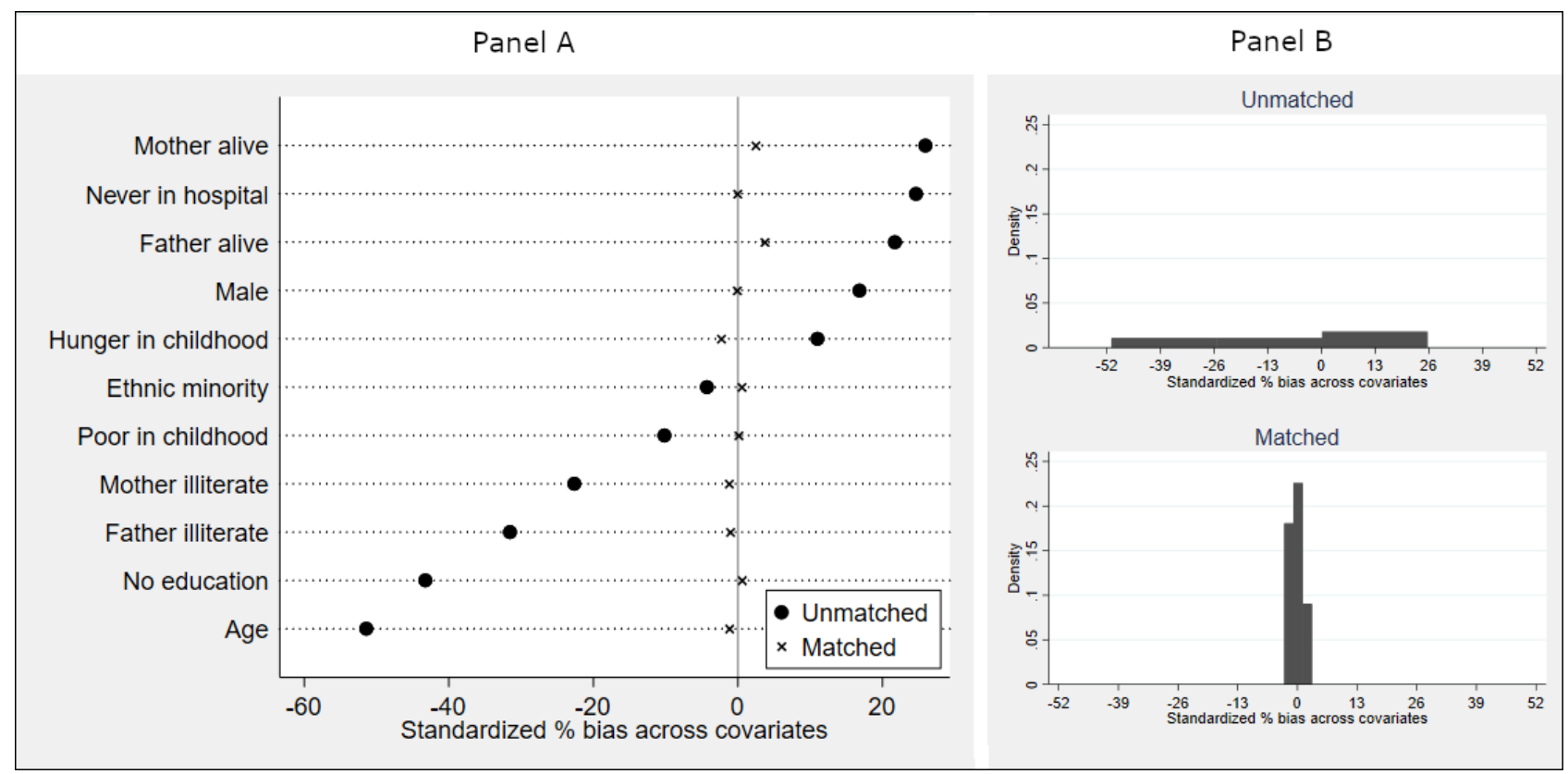

Notes: Estimates obtained by using the CHARLS cross-sectional sample of observations present in the years of schooling variable, including only individuals within the common support region $(N=16,493)$ and using a $K=8$ NN matching algorithm.

Figure 2 Propensity score (kernel) density before and after matching (IPW).

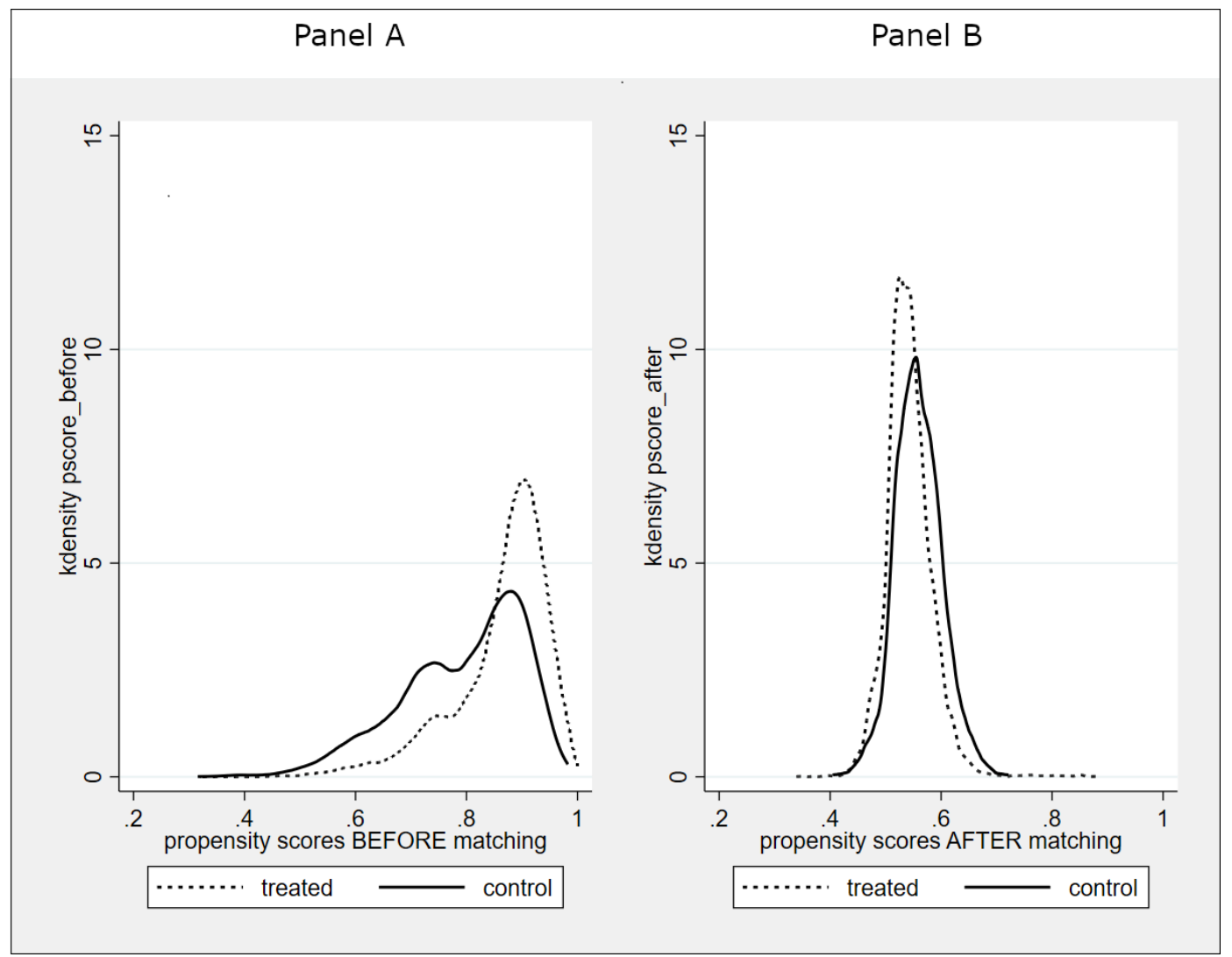

Notes: Estimates obtained by using the CHARLS cross-sectional sample of observations present in the years of schooling variable, including only individuals within the common support region and using an IPW matching technique. 
Table 1 ATT estimates for education and cognitive abilities

\begin{tabular}{|c|c|c|c|c|c|c|}
\hline \multirow[b]{2}{*}{ Dependent variable } & \multicolumn{2}{|c|}{ Nearest neighbor } & \multicolumn{2}{|c|}{ Nearest neighbor $(k=8)$} & \multicolumn{2}{|c|}{ IPW } \\
\hline & ATT & T-stat & ATT & T-stat & ATT & T-stat \\
\hline Years of schooling & 1.210 & 12.872 & 1.075 & 15.580 & 1.246 & 12.422 \\
\hline Drawing & 0.092 & 7.077 & 0.090 & 9.000 & 0.089 & 7.639 \\
\hline Serial 7 & 0.065 & 6.500 & 0.065 & 8.125 & 0.081 & 10.957 \\
\hline Name year & 0.068 & 5.231 & 0.064 & 6.400 & 0.075 & 7.352 \\
\hline Name month & 0.025 & 2.273 & 0.030 & 3.750 & 0.044 & 6.216 \\
\hline Name day & 0.034 & 2.615 & 0.038 & 3.800 & 0.049 & 6.004 \\
\hline Name weekday & 0.078 & 6.000 & 0.074 & 7.400 & 0.082 & 9.074 \\
\hline Immediate recall & 0.026 & 5.200 & 0.033 & 8.250 & 0.075 & 7.352 \\
\hline Delayed recall & 0.032 & 6.400 & 0.039 & 9.750 & 0.034 & 7.148 \\
\hline Mental health & 0.012 & 5.202 & 0.038 & 11.075 & 0.037 & 7.626 \\
\hline \multirow[t]{2}{*}{ Episodic memory } & 0.060 & 2.841 & 0.059 & 9.496 & 0.029 & 11.257 \\
\hline & \multicolumn{2}{|c|}{ Kernel } & \multicolumn{2}{|c|}{ LLR } & \multicolumn{2}{|c|}{ Mahalanobis } \\
\hline Dependent variable & ATT & T-stat & ATT & T-stat & ATT & T-stat \\
\hline Years of schooling & 1.229 & 20.831 & 1.069 & 17.242 & 1.066 & 12.843 \\
\hline Drawing & 0.089 & 11.125 & 0.081 & 9.000 & 0.085 & 7.083 \\
\hline Serial 7 & 0.075 & 10.714 & 0.070 & 10.000 & 0.083 & 9.222 \\
\hline Name year & 0.067 & 8.375 & 0.067 & 8.375 & 0.073 & 6.636 \\
\hline Name month & 0.039 & 5.571 & 0.033 & 4.714 & 0.040 & 4.000 \\
\hline Name day & 0.042 & 5.250 & 0.038 & 4.222 & 0.059 & 5.364 \\
\hline Name weekday & 0.077 & 8.556 & 0.076 & 8.444 & 0.060 & 5.000 \\
\hline Immediate recall & 0.038 & 12.667 & 0.033 & 11.000 & 0.037 & 9.250 \\
\hline Delayed recall & 0.042 & 14.000 & 0.037 & 9.250 & 0.042 & 8.400 \\
\hline Mental health & 0.027 & 11.080 & 0.026 & 10.038 & 0.032 & 9.441 \\
\hline Episodic memory & 0.043 & 11.972 & 0.038 & 10.184 & 0.042 & 8.673 \\
\hline
\end{tabular}

Notes: Estimates obtained using the CHARLS pooled sample of observations present in the respective outcome considered and including only individuals within the common support region. 
Table 2 ATT estimates for education and cognitive abilities (exact and coarsened exact matching)

\begin{tabular}{|c|c|c|c|c|}
\hline \multirow{2}{*}{ Dependent variable } & \multicolumn{2}{|c|}{ CEM } & \multicolumn{2}{|c|}{ Exact matching } \\
\hline & ATT & T-stat & ATT & T-stat \\
\hline Years of schooling & 1.019 & 10.666 & 1.120 & 12.142 \\
\hline Drawing & 0.077 & 6.677 & 0.092 & 7.836 \\
\hline Serial 7 & 0.059 & 7.353 & 0.068 & 8.326 \\
\hline Name year & 0.056 & 6.004 & 0.063 & 7.325 \\
\hline Name month & 0.027 & 3.654 & 0.033 & 4.975 \\
\hline Name day & 0.029 & 4.085 & 0.037 & 4.771 \\
\hline Name weekday & 0.077 & 7.730 & 0.078 & 9.280 \\
\hline Immediate recall & 0.029 & 7.568 & 0.042 & 9.878 \\
\hline Delayed recall & 0.032 & 6.893 & 0.048 & 9.427 \\
\hline Mental health & 0.024 & 9.301 & 0.026 & 10.674 \\
\hline Episodic memory & 0.033 & 6.925 & 0.049 & 9.412 \\
\hline \multicolumn{5}{|c|}{ Sample size } \\
\hline & Control & Treated & Control & Treated \\
\hline Matched & 6,217 & 30,000 & 6,576 & 34,796 \\
\hline Unmatched & 435 & 7,476 & 76 & 2,680 \\
\hline
\end{tabular}

Notes: Estimates obtained using the CHARLS pooled sample of observations present in the respective outcome considered and including only individuals within the common support region. The bottom part of the table refers to the sample size by treatment group before and after matching for the model using years of schooling as the outcome variable. CEM, coarsened exact matching. 
Table 6 Correlated random effects (IPW models)

\begin{tabular}{|c|c|c|c|c|c|c|c|c|c|c|}
\hline & Draw & Serial 7 & $\begin{array}{l}\text { Name } \\
\text { year }\end{array}$ & $\begin{array}{l}\text { Name } \\
\text { month }\end{array}$ & Name day & $\begin{array}{c}\text { Name } \\
\text { weekday }\end{array}$ & $\begin{array}{l}\text { Immediate } \\
\text { recall }\end{array}$ & $\begin{array}{c}\text { Delayed } \\
\text { word recall }\end{array}$ & $\begin{array}{l}\text { Mental } \\
\text { health }\end{array}$ & $\begin{array}{l}\text { Episodic } \\
\text { memory }\end{array}$ \\
\hline $\begin{array}{l}\text { Vaccine } \\
\text { in childhood }\end{array}$ & $\begin{array}{r}0.071 \\
(0.006)^{* *}\end{array}$ & $\begin{array}{r}0.065 \\
(0.005)^{* *}\end{array}$ & $\begin{array}{r}0.050 \\
(0.006)^{* *}\end{array}$ & $\begin{array}{r}0.023 \\
(0.005)^{* *}\end{array}$ & $\begin{array}{c}0.026 \\
(0.006)^{* *}\end{array}$ & $\begin{array}{c}0.068 \\
(0.007)^{* *}\end{array}$ & $\begin{array}{c}0.032 \\
(0.002)^{* *}\end{array}$ & $\begin{array}{c}0.036 \\
(0.003)^{* *}\end{array}$ & $\begin{array}{c}0.021 \\
(0.002)^{* *}\end{array}$ & $\begin{array}{c}0.038 \\
(0.003)^{* *}\end{array}$ \\
\hline Age (years) & $\begin{array}{r}-0.011 \\
(0.002)^{* *}\end{array}$ & $\begin{array}{r}-0.008 \\
(0.001)^{* *}\end{array}$ & $\begin{array}{r}-0.001 \\
(0.001)\end{array}$ & $\begin{array}{r}-0.016 \\
(0.001)^{* *}\end{array}$ & $\begin{array}{c}-0.018 \\
(0.002)^{* *}\end{array}$ & $\begin{array}{c}0.009 \\
(0.002)^{* *}\end{array}$ & $\begin{array}{c}-0.007 \\
(0.001)^{* *}\end{array}$ & $\begin{array}{c}-0.009 \\
(0.001)^{* *}\end{array}$ & $\begin{array}{c}-0.016 \\
(0.003)^{* *}\end{array}$ & $\begin{array}{c}-0.095 \\
(0.006)^{* *}\end{array}$ \\
\hline Male & $\begin{array}{r}0.191 \\
(0.006)^{* *}\end{array}$ & $\begin{array}{r}0.159 \\
(0.005)^{* *}\end{array}$ & $\begin{array}{r}0.185 \\
(0.006)^{* *}\end{array}$ & $\begin{array}{r}0.080 \\
(0.005)^{* *}\end{array}$ & $\begin{array}{c}0.044 \\
(0.006)^{* *}\end{array}$ & $\begin{array}{l}-0.013 \\
(0.007)^{*}\end{array}$ & $\begin{array}{c}0.009 \\
(0.002)^{* *}\end{array}$ & $\begin{array}{c}0.006 \\
(0.003)^{*}\end{array}$ & $\begin{array}{c}0.438 \\
(0.017)^{* *}\end{array}$ & $\begin{array}{c}0.062 \\
(0.028)^{*}\end{array}$ \\
\hline $\begin{array}{l}\text { Income } \\
(10,000 ¥)\end{array}$ & $\begin{array}{r}0.002 \\
(0.002)\end{array}$ & $\begin{array}{r}0.001 \\
(0.002)\end{array}$ & $\begin{array}{r}0.001 \\
(0.002)\end{array}$ & $\begin{array}{r}0.002 \\
(0.002)\end{array}$ & $\begin{array}{c}0.005 \\
(0.002)^{*}\end{array}$ & $\begin{array}{l}-0.001 \\
(0.003)\end{array}$ & $\begin{array}{c}0.000 \\
(0.001)\end{array}$ & $\begin{array}{c}0.002 \\
(0.001)\end{array}$ & $\begin{array}{c}0.005 \\
(0.005)\end{array}$ & $\begin{array}{c}0.017 \\
(0.010)\end{array}$ \\
\hline $\begin{array}{l}\text { Food } \\
(10,000 ¥)\end{array}$ & $\begin{array}{r}0.219 \\
(0.047)^{* *}\end{array}$ & $\begin{array}{r}0.028 \\
(0.035)\end{array}$ & $\begin{array}{r}0.002 \\
(0.041)\end{array}$ & $\begin{array}{l}-0.025 \\
(0.038)\end{array}$ & $\begin{array}{c}0.050 \\
(0.048)\end{array}$ & $\begin{array}{l}-0.087 \\
(0.056)\end{array}$ & $\begin{array}{l}-0.040 \\
(0.018)^{*}\end{array}$ & $\begin{array}{l}-0.032 \\
(0.020)\end{array}$ & $\begin{array}{c}0.124 \\
(0.103)\end{array}$ & $\begin{array}{l}-0.334 \\
(0.208)\end{array}$ \\
\hline $\begin{array}{l}\text { Mean(s) } \\
\text { of age }\end{array}$ & $\begin{array}{r}0.001 \\
(0.002)\end{array}$ & $\begin{array}{r}0.003 \\
(0.001)^{*}\end{array}$ & $\begin{array}{r}-0.008 \\
(0.001)^{* *}\end{array}$ & $\begin{array}{r}0.012 \\
(0.001)^{* *}\end{array}$ & $\begin{array}{c}0.014 \\
(0.002)^{* *}\end{array}$ & $\begin{array}{c}-0.013 \\
(0.002)^{* *}\end{array}$ & $\begin{array}{c}0.002 \\
(0.001)^{* *}\end{array}$ & $\begin{array}{c}0.004 \\
(0.001)^{* *}\end{array}$ & $\begin{array}{c}-0.012 \\
(0.004) * *\end{array}$ & $\begin{array}{c}0.042 \\
(0.007)^{* *}\end{array}$ \\
\hline $\begin{array}{l}\text { Mean(s) } \\
\text { of food }\end{array}$ & $\begin{array}{r}0.149 \\
(0.077)\end{array}$ & $\begin{array}{r}0.147 \\
(0.064)^{*}\end{array}$ & $\begin{array}{r}0.252 \\
(0.069)^{* *}\end{array}$ & $\begin{array}{r}0.138 \\
(0.060)^{*}\end{array}$ & $\begin{array}{c}0.119 \\
(0.075)\end{array}$ & $\begin{array}{c}0.411 \\
(0.087)^{* *}\end{array}$ & $\begin{array}{c}0.184 \\
(0.030)^{* *}\end{array}$ & $\begin{array}{c}0.196 \\
(0.034)^{* *}\end{array}$ & $\begin{array}{c}1.041 \\
(0.195)^{* *}\end{array}$ & $\begin{array}{c}2.063 \\
(0.349)^{* *}\end{array}$ \\
\hline $\begin{array}{l}\text { Mean(s) } \\
\text { of income }\end{array}$ & $\begin{array}{r}0.015 \\
(0.003)^{* *}\end{array}$ & $\begin{array}{r}0.016 \\
(0.003)^{* *}\end{array}$ & $\begin{array}{r}0.014 \\
(0.003)^{* *}\end{array}$ & $\begin{array}{r}0.011 \\
(0.003)^{* *}\end{array}$ & $\begin{array}{c}0.013 \\
(0.003)^{* *}\end{array}$ & $\begin{array}{c}0.027 \\
(0.003)^{* *}\end{array}$ & $\begin{array}{c}0.008 \\
(0.001)^{* *}\end{array}$ & $\begin{array}{c}0.007 \\
(0.001)^{* *}\end{array}$ & $\begin{array}{c}0.066 \\
(0.008)^{* *}\end{array}$ & $\begin{array}{c}0.070 \\
(0.014)^{* *}\end{array}$ \\
\hline Constant & $\begin{array}{r}1.064 \\
(0.022)^{* *}\end{array}$ & $\begin{array}{r}0.707 \\
(0.019)^{* *}\end{array}$ & $\begin{array}{r}1.118 \\
(0.021)^{* *}\end{array}$ & $\begin{array}{r}1.012 \\
(0.017)^{* *}\end{array}$ & $\begin{array}{c}0.882 \\
(0.021)^{* *}\end{array}$ & $\begin{array}{c}0.836 \\
(0.024)^{* *}\end{array}$ & $\begin{array}{c}0.616 \\
(0.009)^{* *}\end{array}$ & $\begin{array}{c}0.559 \\
(0.010)^{* *}\end{array}$ & $\begin{array}{c}4.198 \\
(0.061)^{* *}\end{array}$ & $\begin{array}{c}5.894 \\
(0.102)^{* *}\end{array}$ \\
\hline R2-within & 0.004 & 0.003 & 0.000 & 0.011 & 0.009 & 0.002 & 0.011 & 0.014 & 0.001 & 0.015 \\
\hline R2-between & 0.147 & 0.118 & 0.136 & 0.049 & 0.028 & 0.041 & 0.116 & 0.114 & 0.148 & 0.116 \\
\hline R2-overall & 0.083 & 0.065 & 0.081 & 0.031 & 0.017 & 0.023 & 0.070 & 0.072 & 0.091 & 0.073 \\
\hline$N$ & 31,169 & 31,470 & 30,959 & 30,957 & 30,958 & 28,763 & 29,326 & 29,253 & 30,253 & 29,145 \\
\hline
\end{tabular}

Notes: Estimates obtained using the CHARLS longitudinal sample of observations present in the respective outcome considered and including only individuals within the common support region. Standard errors clustered at the year of birth level. $* \mathrm{p}<0.05, * * \mathrm{p}<0.01, * * * \mathrm{p}<0.001$. 
Table 3 Descriptive statistics: placebo outcomes by treatment group

\begin{tabular}{l|cc|cc|cc|cc}
\hline \multirow{2}{*}{\multicolumn{1}{c|}{ Variable }} & \multicolumn{2}{|c|}{ Full sample } & \multicolumn{2}{c|}{ Treated } & \multicolumn{2}{c|}{ Control } & \multicolumn{2}{c}{ Before matching } \\
\cline { 2 - 9 } & Mean & SD & Mean & SD & Mean & SD & Difference & T-test \\
\hline Ever smoke & 0.43 & 0.49 & 0.44 & 0.50 & 0.39 & 0.49 & 0.05 & 6.91 \\
Share of living siblings & 0.84 & 0.26 & 0.85 & 0.25 & 0.79 & 0.30 & 0.06 & 16.02 \\
\hline
\end{tabular}

Note: Estimates obtained using the CHARLS cross-sectional sample of observations present in the years of schooling variable $(N=16,602)$. $S D$, standard deviation.

Table 4 Placebo tests

\begin{tabular}{|c|c|c|c|c|c|c|}
\hline \multirow{2}{*}{ Dependent variable } & \multicolumn{2}{|c|}{ Nearest neighbor } & \multicolumn{2}{|c|}{ Nearest neighbor $(k=8)$} & \multicolumn{2}{|c|}{ IPW } \\
\hline & ATT & T-stat & ATT & T-stat & ATT & T-stat \\
\hline \multirow{4}{*}{$\begin{array}{l}\text { Ever smoke } \\
\text { Share of living siblings }\end{array}$} & -0.002 & -0.2 & -0.004 & -0.5 & -0.01 & -1.451 \\
\hline & -0.001 & -0.167 & -0.002 & -0.4 & -0.001 & -0.31 \\
\hline & \multicolumn{2}{|c|}{ Kernel } & \multicolumn{2}{|c|}{ LLR } & \multicolumn{2}{|c|}{ Mahalanobis } \\
\hline & ATT & T-stat & ATT & T-stat & ATT & T-stat \\
\hline \multirow{4}{*}{$\begin{array}{l}\text { Ever smoke } \\
\text { Share of living siblings }\end{array}$} & 0.005 & 0.625 & -0.015 & -1.25 & 0.009 & 0.818 \\
\hline & 0.001 & 0.008 & -0.003 & -0.429 & 0.004 & 0.667 \\
\hline & \multicolumn{2}{|c|}{ CEM } & \multicolumn{2}{|c|}{ Exact Matching } & \multicolumn{2}{|c|}{ CRE IPW } \\
\hline & ATT & T-stat & ATT & T-stat & ATT & T-stat \\
\hline \multirow{2}{*}{$\begin{array}{l}\text { Ever smoke } \\
\text { Share of living siblings }\end{array}$} & -0.009 & -0.78 & -0.007 & -0.636 & -0.006 & -1.12 \\
\hline & 0.002 & 0.373 & 0.025 & 2.72 & -0.003 & -0.82 \\
\hline
\end{tabular}

Notes: Estimates obtained using the CHARLS pooled sample of observations present in the respective outcome considered and including only individuals within the common support region. 


\begin{tabular}{|c|c|c|c|c|}
\hline Variable & Survey Question & $\begin{array}{c}\text { Type } \\
\text { (original) }\end{array}$ & Type (final) & Description \\
\hline Year of schooling & $\begin{array}{l}\text { What is the highest level of education you } \\
\text { have completed? }\end{array}$ & categorical & continuous & $\begin{array}{l}\text { transformation } \\
\text { based on Chinese } \\
\text { education system }\end{array}$ \\
\hline Draw & $\begin{array}{l}\text { Do you see this picture? Please draw that } \\
\text { picture on this paper. }\end{array}$ & dummy & dummy & $\begin{array}{l}1 \text { if drew the } \\
\text { picture }\end{array}$ \\
\hline Serial 7 & $\begin{array}{l}\text { Let's try some subtraction of numbers this } \\
\text { time. What does } 100 \text { minus } 7 \text { equal? ... and } 7 \\
\text { from that? ( } 5 \text { times) }\end{array}$ & count & share & $\begin{array}{l}\text { mean of correct } \\
\text { answers }\end{array}$ \\
\hline Name year & Please tell me today's date. & dummy & dummy & 1 if year is correct \\
\hline Name month & Please tell me today's date. & dummy & dummy & $\begin{array}{l}1 \text { if month is } \\
\text { correct }\end{array}$ \\
\hline Name weekday & Please tell me today's date. & dummy & dummy & $\begin{array}{l}1 \text { if weekday is } \\
\text { correct }\end{array}$ \\
\hline Name day & Please tell me today's date. & dummy & dummy & 1 if day is correct \\
\hline Immediate work recall & $\begin{array}{l}\text { We are going to read a list consisting of } 10 \\
\text { words, and we would like you to memorize as } \\
\text { many as you can. }\end{array}$ & count & share & $\begin{array}{l}\text { share of recalled } \\
\text { words }\end{array}$ \\
\hline Delayed word recall & $\begin{array}{l}\text { Please tell me any of the words that you } \\
\text { remember now ( } 4 \text { minutes after). }\end{array}$ & count & share & $\begin{array}{l}\text { share of recalled } \\
\text { words }\end{array}$ \\
\hline Episodic memory & $\begin{array}{l}\text { Aggregates immediate and delayed work } \\
\text { recall variables }\end{array}$ & count & share & $\begin{array}{l}\text { mean of recalled } \\
\text { words ( } 20 \text { words) }\end{array}$ \\
\hline Mental health & $\begin{array}{l}\text { Aggregates drawing and today's date } \\
\text { questions }\end{array}$ & count & share & $\begin{array}{l}\text { share of correct } \\
\text { answers } \\
\text { dichotomous } \\
\text { items) }\end{array}$ \\
\hline
\end{tabular}

\section{Placebo Variables}

Drinking (habitually)

Ever smoke

Share of living siblings
How many of your biological siblings are still alive? How many of your biological siblings have died?

\section{Survey Question}

How often did you drink liquor, including white liquor, whisky, and others per month in the last year?

Have you ever chewed tobacco, smoked a pipe, smoked self-rolled cigarettes, or smoked cigarettes/cigars?

\begin{tabular}{|c|c|c|}
\hline $\begin{array}{c}\text { Type } \\
\text { (original) }\end{array}$ & Type (final) & Description \\
\hline categorical & dummy & $\begin{array}{l}1 \text { if every day or } \\
\text { more }\end{array}$ \\
\hline dummy & dummy & 1 if yes \\
\hline count & continuous & $\begin{array}{l}\text { share of living } \\
\text { siblings over the } \\
\text { total (it excludes } \\
\text { observations } \\
\text { without any } \\
\text { sibling) }\end{array}$ \\
\hline
\end{tabular}


Table A.2 Conditioning variables survey questions

\begin{tabular}{|c|c|c|c|c|}
\hline Variable & Survey Question & $\begin{array}{c}\text { Type } \\
\text { (original) }\end{array}$ & Type (final) & Description \\
\hline $\begin{array}{l}\text { Mother } \\
\text { alive }\end{array}$ & Is your biological mother alive? & dummy & dummy & 1 if mother alive \\
\hline Father alive & Is your biological father alive? & dummy & dummy & 1 if father alive \\
\hline $\begin{array}{l}\text { Mother } \\
\text { illiterate }\end{array}$ & $\begin{array}{l}\text { What is the highest level of education your biological } \\
\text { mother completed? }\end{array}$ & categorical & dummy & $\begin{array}{l}1 \text { if no formal } \\
\text { education (vs. any } \\
\text { other) }\end{array}$ \\
\hline $\begin{array}{l}\text { Father } \\
\text { illiterate }\end{array}$ & $\begin{array}{l}\text { What is the highest level of education your biological } \\
\text { father completed? }\end{array}$ & categorical & dummy & $\begin{array}{l}1 \text { if no formal } \\
\text { education (vs. any } \\
\text { other) }\end{array}$ \\
\hline $\begin{array}{l}\text { Ethnic } \\
\text { minority }\end{array}$ & What ethnicity is [the name of the respondent]? & categorical & dummy & $\begin{array}{l}\text { Han (vs. any } \\
\text { other) }\end{array}$ \\
\hline $\begin{array}{l}\text { Poor in } \\
\text { childhood }\end{array}$ & $\begin{array}{l}\text { When you were a child before age } 17 \text {, compared with } \\
\text { the average family in the same } \\
\text { community/village at that time, how was your family's } \\
\text { financial situation? }\end{array}$ & categorical & dummy & $\begin{array}{l}1 \text { if worse or a lo } \\
\text { worse off than } \\
\text { others }\end{array}$ \\
\hline $\begin{array}{l}\text { No child } \\
\text { education }\end{array}$ & $\begin{array}{l}\text { Did you ever miss school for a month or more because } \\
\text { of a health condition before you were } 15 \text { years old? }\end{array}$ & categorical & dummy & $\begin{array}{l}1 \text { if never had any } \\
\text { education before } \\
\text { subject was } 15 \\
\text { years old }\end{array}$ \\
\hline $\begin{array}{l}\text { Hunger in } \\
\text { childhood }\end{array}$ & $\begin{array}{l}\text { At what age ranges did this (your family had no } \\
\text { enough food to eat) happen? }\end{array}$ & categorical & dummy & $\begin{array}{l}1 \text { if hunger before } \\
\text { age } 17\end{array}$ \\
\hline $\begin{array}{l}\text { Never been } \\
\text { in hospital }\end{array}$ & $\begin{array}{l}\text { Can you remember the first time you got to see a } \\
\text { doctor? What was the type of the } \\
\text { doctor? }\end{array}$ & categorical & dummy & $\begin{array}{l}1 \text { if never seen a } \\
\text { doctor }\end{array}$ \\
\hline Age & Imputed age from exact date of birth & continuous & continuous & Age in years \\
\hline
\end{tabular}


Table A.3 ATT estimates for education and cognitive abilities (excluding childhood education from the set of conditioning variables)

\begin{tabular}{|c|c|c|c|c|c|c|}
\hline \multirow{2}{*}{ Dependent variable } & \multicolumn{2}{|c|}{ Nearest neighbor } & \multicolumn{2}{|c|}{ Nearest neighbor $(k=8)$} & \multicolumn{2}{|c|}{ IPW } \\
\hline & ATT & T-stat & ATT & T-stat & ATT & T-stat \\
\hline Years of schooling & 1.551 & 15.827 & 1.526 & 22.776 & 1.252 & 12.178 \\
\hline Drawing & 0.112 & 8.000 & 0.113 & 11.300 & 0.091 & 7.684 \\
\hline Serial 7 & 0.090 & 8.182 & 0.098 & 12.250 & 0.081 & 10.871 \\
\hline Name year & 0.099 & 7.615 & 0.092 & 10.222 & 0.074 & 7.093 \\
\hline Name month & 0.045 & 4.091 & 0.055 & 6.875 & 0.043 & 5.884 \\
\hline Name day & 0.058 & 4.462 & 0.063 & 7.000 & 0.048 & 5.626 \\
\hline Name weekday & 0.092 & 6.571 & 0.085 & 8.500 & 0.079 & 8.728 \\
\hline Immediate recall & 0.034 & 6.800 & 0.040 & 10.000 & 0.035 & 7.240 \\
\hline Delayed recall & 0.034 & 5.667 & 0.045 & 11.250 & 0.038 & 7.843 \\
\hline Mental health & 0.078 & 8.667 & 0.079 & 13.167 & 0.064 & 10.194 \\
\hline Episodic memory & 0.030 & 6.000 & 0.040 & 13.333 & 0.029 & 11.257 \\
\hline \multirow{2}{*}{ Dependent variable } & \multicolumn{2}{|c|}{ Kernel } & \multirow{2}{*}{\multicolumn{2}{|c|}{ LLR }} & \multicolumn{2}{|c|}{ Mahalanobis } \\
\hline & ATT & T-stat & & & ATT & T-stat \\
\hline Years of schooling & 1.602 & 28.105 & 1.345 & 10.037 & 1.579 & 11.784 \\
\hline Drawing & 0.117 & 14.625 & 0.103 & 5.421 & 0.117 & 6.158 \\
\hline Serial 7 & 0.097 & 16.167 & 0.088 & 5.867 & 0.097 & 6.467 \\
\hline Name year & 0.094 & 11.750 & 0.080 & 4.444 & 0.111 & 6.167 \\
\hline Name month & 0.056 & 8.000 & 0.046 & 3.067 & 0.010 & 0.667 \\
\hline Name day & 0.058 & 7.250 & 0.053 & 2.944 & 0.029 & 1.611 \\
\hline Name weekday & 0.092 & 11.500 & 0.084 & 4.421 & 0.123 & 6.474 \\
\hline Immediate recall & 0.043 & 14.333 & 0.040 & 5.714 & 0.023 & 3.286 \\
\hline Delayed recall & 0.047 & 15.667 & 0.043 & 5.375 & 0.020 & 2.500 \\
\hline Mental health & 0.080 & 16.000 & 0.070 & 5.833 & 0.076 & 6.333 \\
\hline Episodic memory & 0.045 & 15.000 & 0.041 & 5.857 & 0.018 & 2.571 \\
\hline
\end{tabular}

Notes: Estimates obtained using the CHARLS pooled sample of observations present in the respective outcome considered and including only individuals within the common support region. IPW, inverse probability weighting; LLR, local linear regression. 
Table A.4 ATT estimates for education and cognitive abilities (including individuals up to 90 years of age)

\begin{tabular}{|c|c|c|c|c|c|c|}
\hline \multirow{2}{*}{ Dependent variable } & \multicolumn{2}{|c|}{ Nearest neighbor } & \multicolumn{2}{|c|}{ Nearest neighbor $(k=8)$} & \multicolumn{2}{|c|}{ IPW } \\
\hline & ATT & T-stat & ATT & T-stat & ATT & T-stat \\
\hline Years of schooling & 1.176 & 12.511 & 1.138 & 17.242 & 0.803 & 7.912 \\
\hline Drawing & 0.101 & 7.769 & 0.083 & 9.222 & 0.055 & 4.786 \\
\hline Serial 7 & 0.056 & 5.600 & 0.074 & 10.571 & 0.055 & 7.179 \\
\hline Name year & 0.060 & 4.615 & 0.063 & 7.000 & 0.039 & 3.872 \\
\hline Name month & 0.025 & 2.273 & 0.033 & 4.125 & 0.022 & 3.018 \\
\hline Name day & 0.037 & 2.846 & 0.038 & 4.222 & 0.027 & 3.163 \\
\hline Name weekday & 0.079 & 6.077 & 0.079 & 7.900 & 0.062 & 6.873 \\
\hline Immediate recall & 0.025 & 5.000 & 0.035 & 8.750 & 0.027 & 5.797 \\
\hline Delayed recall & 0.036 & 7.200 & 0.040 & 10.000 & 0.030 & 6.270 \\
\hline Mental health & 0.059 & 7.375 & 0.055 & 9.167 & 0.040 & 6.604 \\
\hline Episodic memory & 0.028 & 5.600 & 0.037 & 9.250 & 0.028 & 6.258 \\
\hline \multirow{2}{*}{ Dependent variable } & \multicolumn{2}{|c|}{ Kernel } & \multirow{2}{*}{\multicolumn{2}{|c|}{ LLR }} & \multicolumn{2}{|c|}{ Mahalanobis } \\
\hline & ATT & T-stat & & & ATT & T-stat \\
\hline Years of schooling & 1.221 & 21.421 & 1.026 & 8.079 & 1.029 & 12.549 \\
\hline Drawing & 0.087 & 10.875 & 0.079 & 4.389 & 0.081 & 7.364 \\
\hline Serial 7 & 0.075 & 12.500 & 0.071 & 5.071 & 0.078 & 8.667 \\
\hline Name year & 0.065 & 8.125 & 0.056 & 3.294 & 0.078 & 7.091 \\
\hline Name month & 0.038 & 5.429 & 0.031 & 2.214 & 0.048 & 4.800 \\
\hline Name day & 0.041 & 5.125 & 0.038 & 2.235 & 0.054 & 4.909 \\
\hline Name weekday & 0.078 & 9.750 & 0.072 & 4.000 & 0.076 & 6.333 \\
\hline Immediate recall & 0.038 & 12.667 & 0.033 & 5.500 & 0.037 & 9.250 \\
\hline Delayed recall & 0.042 & 14.000 & 0.036 & 5.143 & 0.037 & 7.400 \\
\hline Mental health & 0.059 & 11.800 & 0.053 & 4.818 & 0.064 & 9.143 \\
\hline Episodic memory & 0.039 & 13.000 & 0.034 & 4.857 & 0.036 & 9.000 \\
\hline
\end{tabular}

Notes: Estimates obtained using the CHARLS pooled sample of observations present in the respective outcome considered and including only individuals within the common support region. IPW, inverse probability weighting; LLR, local linear regression. 